\title{
Análisis fitoquímico de una composición etnofarmacológica a base de seis extractos de plantas para el tratamiento de la hipertensión
}

\section{Analysis phytochemical of a composition etnofarmacológic to base of six extracts of plants for the treatment of the hypertension}

\author{
Carlos Ariel Rentería Jiménez ${ }^{1}$, Manuel Arcindo García Martínez ${ }^{2}$, Soelia Mosquera Córdoba ${ }^{3}$

\section{RESUMEN} \\ Se muestra los resultados del análisis fitoquímicos realizado a una composi- \\ ción etnofarmacéutica de origen natural útil en la prevención y tratamiento \\ de la hipertensión, que consisten de seis extractos de plantas medicinales: \\ extracto acuoso de hojas de guanábana (Annona muricata), extracto acuoso \\ de hojas de aguacate (Persea americana Mili), extracto acuoso de mejorana \\ (Majorana hortensis) extracto acuoso de cogollos de guayaba (Psidium guajava \\ L.), extracto acuoso de ajo (Allium sativum) y extracto acuoso de fruto de borojó \\ (Borojoa patinoi). Se encuentra la presencia de metabolitos secundarios como \\ 1. Investigador de proyectos especiales, Ins- \\ tituto de Investigaciones Ambientales del \\ Pacífico IIAP). Quibdó, Colombia. \\ e-mail:carielrenteria@hotmail.com \\ 2. Investigador Médico Tradicional. Contra- \\ tista IIAP. Quibdó, Colombia. \\ 3. Bióloga. Contratista IIAP. Quibdó, Co- \\ lombia.e-mail: somoco79@yahoo.es \\ Recibido: enero 20, 209 \\ Aceptado: febrero 6, 2009
} ingredientes activos de la composición etnofarmacológica, tales como loscompuestos lactónicos (p.e,. cardiotónicos o térpenlactonas), compuestos fenólicos y leucoantocianidinas.

Palabras clave: Análisis fitoquímico; Etnofarmacología; Extractos acuosos; Hipertensión; Plantas medicinales; Metabolitos secundarios.

\begin{abstract}
The present communication shows the results of analysis phytochemical carried out to a composition etnofarmaceutic of useful natural origin in the prevention and treatment of the hypertension that consist of six extracts of medicinal plants: I summarize watery of guanábana leaves (Annona muricata), I summarize watery of avocado leaves (American Persea Mili), I summarize watery of marjoram (Majorana hortensis) I summarize watery of guava hearts (Psidium guajava L.), I summarize watery of garlic (Allium sativum) and watery extract of borojó fruit (Borojoa patinoi). Results that they show the presence of secondary metabolites as active ingredients of the composition etnofarmacologic, such as: compound lactonics (as for example cardiotonics or terpenlactonas), compound fenolics and leucoantocianidinas.
\end{abstract}

Keywords: Analysis phytochemistric; Etnofarmacological; Watery extracts; Hypertension; Medicinal plants; Secondary metabolites.

\section{INTRODUCCIÓN}

La hipertensión arterial ( HTA) entendida como enfermedad crónica asintomática que se caracteriza por una elevación de presión arterial sistólica (PAS) mayor o igual a $120 \mathrm{~mm} \mathrm{Hg}$ y una presión arterial diastólica(PAD) mayor o igual a $80 \mathrm{~mm}$ $\mathrm{Hg}$ (Joint National Comitte on Prevention, Detection, and
Treatment of High Blood Pressure 2003), se considera hoy como una de las principales problemáticas de salud pública. Actualmente 7,1 millones de personas mueren como resultado de tensión arterial elevada, reconociéndose como una de las tres primeras causas de morbi-mortalidad mundial y nacional, uno de los primeros lugares de causas de incapacidad, uno de los principales motivos de consulta médica y una 


\section{Bioetnia Volumen 6 No 1 (enero-junio), 2009}

enfermedad con serias repercusiones a nivel económico y social (Bacon et al. 2004; Barrera et al. 2000; Blumenthal et al. 2002; Kaplan 2000 citado por Fernández et al. 2003; JNC-VII 2003; OMS 2005; OPS 2003; Sheu et al. 2003; Velasco y Hernández 2001; Whelton et al. 2002). En Colombia, se estima que más de 10 millones de personas presentan HTA $(22,8 \%$ de la población adulta), siendo la región pacifica colombiana la que presenta la prevalencia de hipertensión más elevada $(28 \%)^{*}$.

Los planteamientos de la OMS en relación con la importancia de detener la epidemia mundial de enfermedades crónicas, refuerzan la necesidad de tener a disposición estrategias de intervención eficaces y al alcance de todas las personas afectadas, y es aquí donde la búsqueda de fuentes terapéuticas en el reino vegetal constituye una alternativa viable.

Las comunidades negras del Pacifico colombiano no han sido ajenas a esta costumbre de utilizar tratamientos médicos tradicionales a base de extractos de plantas medicinales para el manejo de la hipertensión y dentro de esta perspectiva, han introducido dentro de su acerbo medico tradicional la preparación y utilización de distintas composiciones etnofarmacológica.

En este artículo se presentan las características y propiedades etnomedicinales de una composición etnofarmacológica, propuesta por el médico tradicional Manuel Arcindo García Martínez para tratar la hipertensión con una composición que se obtiene a partir de la combinación de seis extractos acuosos de plantas medicinales: extracto acuoso de hojas de guanábana (Annona muricata), extracto acuoso de hojas de aguacate (Persea americana Mili), extracto acuoso de mejorana (Majorana hortensis) extracto acuoso de cogollos de guayaba (Psidium guajava L.), extracto acuoso de ajo (Allium sativum) y extracto acuoso de fruto de borojó (Borojoa patinoi).

La A. muricata (guanábana) de la familia Annonaceae, es un árbol que alcanza hasta los 10 metros de altura, de follaje compacto, hojas simples, coriáceas verde oscuro, grandes y brillantes; flores bisexuales solitarias o en pares, en tallos cortos que brotan de las ramas viejas; cáliz con tres sépalos diminutos e inconspicuos de color verde; y corola con seis pétalos de color amarillo. El fruto es una baya colectiva o sincarpo, de forma acorazonada u ovoide, con pericarpio (cáscara) verdoso con tubérculos espiniformes carnosos, la pulpa es blanca y jugosa de sabor agridulce, las semillas de color negro lustroso o castaño (Palomino 2007).

Numerosos principios bioactivos y fitoquímicos encontrados en la guanábana confirman muchos de sus usos en la

* Rodríguez, J., Ruiz, F., Peñaloza, E., Eslava, J., Gómez, L.C., Sánchez, H., et al. Encuesta Nacional de Salud 2007. Resultados nacionales. medicina tradicional y han sido validados por estudios científicos. Los estudios más tempranos datan entre 1941 y 1962 ; otros realizados por diferentes investigadores demostraron que la corteza así como también las hojas tenían actividad hipotensora, antiespasmódica, vasodilatadora, relajante muscular y actividades cardiodepresoras en animales. Se ha verificado sus propiedades hipotensoras en ratas con las hojas de guanábana (Hasrat et al. 1997, citado por Palomino 2007).

Elaguacate (Persea americana Mili) de la familia Lauraceae, es un árbol grande o de tamaño mediano, frecuentemente de 20 metros de alto, con una copa muy densa en donde se encuentra un fruto que tiene forma ovalada o esférica. Los extractos acuosos de hojas de aguacate, además de su alto contenido de aceite esencial, poseen dopamina y serotonina, flavonoides derivados del quercetol, perseita, persiteol y un principio amargo llamado abacatina (Gupta 1995).

La mejorana(Origanum majorana), es una hierba perenne de la familia lamiaceae, cultivada por su uso aromático, que recuerda al pino y a los cítricos. Las matas alcanzan un tamaño de $60 \mathrm{~cm}$ de altura, algo leñosos en la base, hojas aovadas, enteras, blanquecinas y lanuginosas. Las diminutas flores labiadas surgen reunidas en ramilletes terminales, suelen ser blancas o rosadas. Las semillas son redondas, menudas y rojizas. La planta contiene taninos, compuestos minerales, ácidos fenólicos (cafeico, clorogénico y rosmariníco), flavonoides y aceites esenciales, que contienen $\alpha$-pineno, canfeno, sabineno, $\beta$-pineno, mirceno, felandreno, $\alpha$ terpineno, p-cimeno, limoneno, linanlool, alcanfor, terpineol, isoborneol, geraniol, acetato de bornilo, timol, $\beta$-cariofileno, humuleno y carvacrol (Sarer et al. 1982; Vera 1999).

La guayaba (Psidium guajava) es una planta perteneciente a la familia Myrtaceae, es un árbol con tronco de corteza suave, delgada rojo-café, con escamas que caen; hojas verdes, opuestas, elípticas u oblongas, redondeadas en el ápice y base; flores axilares, solitarias, blancas; fruto en baya, aromáticos de diversas formas, según la variedad, carnaza rosada o amarilla. Las hojas contienen compuestos fenólicos (Marquina et al. 2008), polifenoles (Chen y Yen 2007), flavonoides (quercetina) (Lozaya et al. 2002).

El ajo (Allium sativum) es una planta perenne de olor fuerte (Lovatis 1994; Cáceres 1995). Puede llegar hasta un metro de altura (Lovatis 1984). Talo cilíndrico de $50 \mathrm{~cm}$ de altura. Hojas lanceoladas verdes de $30 \mathrm{~cm}$ de largo. Inflorescencia en umbela con flores de pétalos blancos o blancos purpúreos (Cáceres 1995), que por lo general son estériles. Fruto en cápsula triangular (Peris et al. 1995). Las flores son de color blanco-rosado (Lovatis 1994), la raíz es un bulbo redondeado constituido por gajos de sabor picante (Lovatis 1994; Cáceres 1995). El bulbo contiene aceite volátil (1-3\%) sulfurado (disfulfuro de alilo) (Cabrera y Mantilla 1996), sulfóxido de S-alil(L)-(+)-cisteína oaliína(0,2\%)(Hamon 
1991); alí́na, fructuosanos, enzimas (peroxidasas, lisozima, desoxirribonucleasas, dosfomonoesterasas), sales minerales (yodo, sílice y azufre), vitaminas A, tiamina, riboflavina, niacina y ácido ascórbico.

El borojó (Borojoa patinoi Cuatr.) es una especie arbórea perteneciente a la familia Rubiaceae, de 3 a $5 \mathrm{~m}$ de altura. Tallo erecto, hojas decusadas, con estípulas bien definidas, coriáceas; planta dioica; flores masculinas en capítulos, cáliz corto, prismático o cónico, generalmente actinomorfas, sésiles, pentámeras y a veces tetrámeras desprovistas de ovario o, si este existe, es rudimentario o no funcional. Las flores femeninas son solitarias y terminales con dos pares de estípulas brácteales y seis estigmas más largos; ovario ínfero, con cáliz umbilicado en la base, seis cavidades y muchos óvulos, corola con seis a nueve pétalos, estambres lineales, vacíos o estériles. El fruto es una baya carnosa de 7 a $12 \mathrm{~cm}$ de largo un diámetro similar, pudiendo ser periforme y generalmente achatado en el ápice, color verde al principio y pardo claro al madurar; pulpa constituida por el mesocarpio y el endocarpio, sin separación aparente con la cáscara. Diferentes análisis fitoquímico realizados a su fruto revelan la presencia de metabolitos secundarios del orden triterpenos (Giordano 2005), esteroles, saponinas y leucoanticianinas (Dwyer 2003), flavonoides (Mosquera et al. 2005).

La composición fitoquímica de los preparaciones etnofarmacológicas usadas por los médicos tradicionales han sido poco o nada descritas, es por ello que el objetivo de este trabajo es mostrar los primeros resultados del tamizaje fitoquímico realizado a una composición etnofarmacológica para el tratamiento médico tradicional de la hipertensión, utilizados por las comunidades negras del departamento del Chocó. Vale la pena resaltar que los resultados aquí presentados hacen parte del proyecto de investigación «Validación de tratamientos basados en medicina tradicional dirigidos a la cura y/o alivio de enfermedades de alta ocurrencia mundial y nacional». Se espera la obtención de patentes etnofarmacológicas liderado por el Instituto de Investigaciones Ambientales del Pacifico «Jhon Von Neumann» (IIAP).

\section{MÉTODOS}

Las plantas medicinales (guanábana, aguacate, mejorana, guayaba y borojó) usadas para la preparación de la composición etnofarmacológica fueron colectadas en el barrio El Poblado, ubicado al sur de la ciudad de Quibdó. El ajo se obtuvo en un mercado local de plantas medicinales de Quibdó. La identificación taxonómica de las plantas medicinales se realizó en el herbario de la Universidad Tecnológica del Chocó «Diego Luis Córdoba». Los nombres de las plantas y de la parte de la planta que se utiliza para la obtención de los extractos que componen la formulación aparecen en la Tabla 1.
Tabla 1

\section{Nombres de las plantas y parte que se utiliza para la obtención de los extractos}

\begin{tabular}{lc}
\hline $\begin{array}{l}\text { Nombre común y } \\
\text { científico }\end{array}$ & $\begin{array}{c}\text { Obtención de los } \\
\text { extractos }\end{array}$ \\
\hline Guanábana (Annona muricata) & hojas \\
Aguacate (Persea americana Mili) & hojas \\
Mejorana (Majorana hortensis) & hojas \\
Guayaba (Psidium guajava L.) & hojas (cogollos) \\
Ajo (Allium sativum) & cabeza (bulbos) \\
Borojó (Borojoa patinoi) & fruto \\
\hline
\end{tabular}

Antes de llevar a cabo el tamizaje fitoquímico a la composición etnofarmacológica, se realizó una revisión de literatura en algunas bases de datos, a fin de identificar estudios de análisis del contenido químico de las plantas que conforman la composición etnofarmacológica para el tratamiento de la hipertensión.

El material vegetal presente en la composición etnofarmacológica para el tratamiento de la hipertensión fue sometido a análisis químico, mediante marcha fitoquímica, donde se utilizaron las siguientes pruebas de reconocimiento:

- Reacción de cloruro férrico para compuestos fenólicos (CF)

- Reacción de proteínas para taninos (TA)

- Reacción de Shinoda para flavonóides (FL)

- Reacción de Rosenheim para leucoantocianidinas (LE)

- Reacción de Kedde para compuestos lactónicos (CA)

- Método de la espuma para saponinas (SA)

- Reacción de Lieberman-Burchard para triterpenoides y/o esteroides (TE)

- Reacción de Borntranger para quinonas (QU)

- Reacciones de Mayer, Valser, Reineckato de Amonio y Dragendorff para alcaloides (AL)

Todos estos análisis se realizaron por triplicado. La Figura 1 resume la metodología utilizada.

\section{DATOSYRESULTADOS}

La revisión de literatura referida a estudios de análisis del contenido químico de las plantas que conforman la composición etnofarmacológica para el tratamiento de la hipertensión, muestra que algunas de estas plantas contienen en su estructura química metabolitos secundarios tales como flavonoides, derivados tritérpenicos, leucoantocianidinas, saponinas, compuestos fenólicos, antocianinas, alicina, entre otros (Tabla2).

El análisis fitoquímico de la composición etnofarma- 
Bioetnia Volumen 6 № 1 (enero-junio), 2009

Tabla 2

Resumen revisión bibliográfica base de datos Current Contents 1998-septiembre 2009

\begin{tabular}{|c|c|c|c|c|c|}
\hline \multicolumn{2}{|c|}{ Nombre } & \multirow{2}{*}{$\begin{array}{l}\text { Parte de la } \\
\text { planta }\end{array}$} & \multirow{2}{*}{$\begin{array}{l}\text { Actividad } \\
\text { biológica }\end{array}$} & \multirow{2}{*}{$\begin{array}{l}\text { Metabolitos } \\
\text { responsables }\end{array}$} & \multirow[t]{2}{*}{ Autor } \\
\hline común & científico & & & & \\
\hline \multirow[t]{14}{*}{ Guayaba } & $\begin{array}{l}\text { Psidium } \\
\text { guajava }\end{array}$ & Cáscara, hojas & Antioxidante & Compuestos fenólicos & $\begin{array}{l}\text { Marquina, et al. } 2008 \\
\text { Chen, et al. } 2007\end{array}$ \\
\hline & & Hojas, semillas & Antimicrobiana & $\begin{array}{l}\text { Extracto etanólico, } \\
\text { Peptido Pg-AMP1, Polifenóles }\end{array}$ & $\begin{array}{l}\text { Pachanawan, et al. } 2008 \\
\text { Pelegrini, et al. } 2008 \\
\text { Yamanaka, Hatano } 2008 \\
\text { Hoque, et al. } 2007 \\
\text { Nair, Chanda } 2007\end{array}$ \\
\hline & & Hojas & Analgésica & Extracto acuoso & Ojewole 2006 \\
\hline & & Hojas & Antiespasmódica & Flavonoides (quercertina) & Lozoya, et al. 2002 \\
\hline & & Hojas & Antidiarréica & Extracto metanólico & Lin, et al. 2002 \\
\hline & & Hojas & Citotóxica & $\begin{array}{l}\text { Polifenoles, (ácido gálico, } \\
\text { quercertina, catequina, } \\
\text { epicatequina, rutina) }\end{array}$ & $\begin{array}{l}\text { Chen, et al. } 2008 \\
\text { Chen y Yen } 2007 \\
\text { Kaileh, et al. } 2007 \\
\text { Seo, et al. } 2005\end{array}$ \\
\hline & & Hojas y cáscaras & & & Cheng, et al. 2009 \\
\hline & & $\begin{array}{l}\text { de fruta } \\
\text { inmadura }\end{array}$ & Hipoglicemiante & $\begin{array}{l}\text { Extractos acuosos, polifenoles } \\
\text { (ácido gálico, quercertina, } \\
\text { catequina), flavonoides }\end{array}$ & $\begin{array}{l}\text { Chuang, et al. } 2008 \\
\text { Rai, et al. } 2009\end{array}$ \\
\hline & & Hojas & $\begin{array}{l}\text { Antiproliferativa y } \\
\text { antiinflamatoria }\end{array}$ & Polifenoles, Quercertina & $\begin{array}{l}\text { Choi, et al. } 2008 \\
\text { Kaileh, et al. } 2007\end{array}$ \\
\hline & & & & & Kawakami, et al. 2009 \\
\hline & & Hojas, flores & Antiparasitaria & Extractos polares y apolares & Brandelli, et al. (2005 \\
\hline & & y semillas & & & Zahir, et al. 2009 \\
\hline & & Hojas & Antitusiva & Extracto & Jaiarj, et al. 1999 \\
\hline & & Hojas & Antinociceptiva & Aceite esencial & Santos, et al. 1998 \\
\hline \multirow[t]{7}{*}{ Aguacate } & Persea & Fruta & Antifúngico & Lípidos de células idioblásticas & Domergue, et al. 2000 \\
\hline & americana & Toda la planta & Antioxidante & Extracto acuoso & Kawakami, et al. 2009 \\
\hline & & Hojas & Insecticida & Extracto acuoso & Koua y Han, 1998 \\
\hline & & Hojas & Antiviral & Flavonoides monoglicosidados & $\begin{array}{l}\text { De Almeida, et al. } 1998 \\
\text { Miranda, et al. } 1997\end{array}$ \\
\hline & & Hojas & Anticonvulsivante & Extracto acuoso & Ojewole y Amabeoku, 2006 \\
\hline & & Fruta & Hepatoprotector & $\begin{array}{l}\text { Compuestos derivados } \\
\text { de ácidos grasos }\end{array}$ & Kawagishi, et al. 2001 \\
\hline & & Hojas & $\begin{array}{l}\text { Inhibidor de hemo- } \\
\text { rragia por acci- } \\
\text { dente ofídico }\end{array}$ & Extracto apolar & Castro, et al. 1999 \\
\hline Mejorana & $\begin{array}{l}\text { Majorana } \\
\text { ortenses } \\
\text { Origanum }\end{array}$ & Aceite esencial & Insecticida & Terpinel-4-ol y Gamma-terpinene & $\begin{array}{l}\text { Abbassy, et al. } 2009 \\
\text { Lamiri, et al. } 2001\end{array}$ \\
\hline
\end{tabular}


Fitoquímica de una composición etnofarmacológica para tratar la hipertensión. CA Rentería et al.

Tabla 2

Resumen revisión bibliográfica base de datos Current Contents 1998-septiembre 2009 (continuación)

\begin{tabular}{|c|c|c|c|c|c|}
\hline \multicolumn{2}{|c|}{ Nombre } & \multirow{2}{*}{$\begin{array}{l}\text { Parte de la } \\
\text { planta }\end{array}$} & \multirow{2}{*}{$\begin{array}{l}\text { Actividad } \\
\text { biológica }\end{array}$} & \multirow{2}{*}{$\begin{array}{l}\text { Metabolitos } \\
\text { responsables }\end{array}$} & \multirow[t]{2}{*}{ Autor } \\
\hline común & científico & & & & \\
\hline & & Hojas, tallos y flores & Antiplaquetaria & Extracto metanólico & Yazdanparast et al. 2008 \\
\hline & & Hojas, tallo y flores & Antioxidante & Compuestos fenólicos & Dorman, et al. 2004 \\
\hline & & Aceite esencial & Antibacterial & $\begin{array}{l}\text { Monoterpenoides del aceite } \\
\text { esencial (linalol, (-)-terpinel-4-ol } \\
\text { y alfa-terpineol }\end{array}$ & Yang, et al. 2009 \\
\hline & & Hojas, tallos y & Actividad & Extracto metanólico & Leeja y Thoppil 2007 \\
\hline & & flores & antifúngica & & Mahady, et al. 2005 \\
\hline & & $\begin{array}{l}\text { Hojas, tallos y } \\
\text { flores }\end{array}$ & $\begin{array}{l}\text { Inhibidor de la AChE } \\
\text { en la enfermedad } \\
\text { de Alzheimer }\end{array}$ & Extracto etanólico & Chuang, et al. 2008 \\
\hline \multirow[t]{2}{*}{ Guanábana } & Annona & Hojas & Hipotensora & Leucoantocianidinas & Yang, et al. 2009 \\
\hline & muricata & Tallos y hojas & Antiprotozoaria & Extracto en etil-acetato & Osorio, et al. 2007 \\
\hline \multirow[t]{11}{*}{ Ajo } & Allium & Hojas & Antiplasmódicas & Extracto pentanoico & Menan, et al. 2006 \\
\hline & satibum & Hojas & insecticida & Flavonoides & Luna, et al. 2005 \\
\hline & & Semillas & Citotóxica & $\begin{array}{l}\text { Acetogeninas anonáceas } \\
\text { monotetrahidrofuranos }\end{array}$ & Liaw, et al. 2002 \\
\hline & & Semillas & Insecticida & Acetogeninas anonáceas & Fontana, et al. 1998 \\
\hline & & Corteza del tallo & Antivírica & $\begin{array}{l}\text { Extractos etanólicos y } \\
\text { metanólicos }\end{array}$ & Betancur-Galvis, et al. 1999 \\
\hline & & Bulbo & Antiviral & Allitridin & Padma, et al. 1998 \\
\hline & & Bulbo & Amebicida & Extracto metanólico & Liu, et al. 2004 \\
\hline & & Bulbo & Antiparasitaria & Alicina & Polat, et al. 2008 \\
\hline & & Bulbo & Antioxidante & $\begin{array}{l}\text { Compuestos fenólicos ácido } \\
\text { gálico), agliconas flavonoides }\end{array}$ & Coppi, et al. 2006 \\
\hline & & & & (querecetina), alicina & Bozin, et al. 2008) \\
\hline & & Bulbo añejo & Antiosteoporótico & Aceite esencial & Mukherjee, et al. 2006 \\
\hline
\end{tabular}

cológica para el tratamiento de la hipertensión se muestra en la Tabla 3.

En la marcha fitoquímica realizada sobre la muestra proporcionada de la composición etnofarmacológica, se obtuvo resultados de presunción muy positiva para la presencia de compuestos lactónicos como cardiotónicos o terpenlactonas, y altamente positiva de compuestos fenólicos y leucoantocianidinas.

\section{DISCUSIÓN}

Los análisis químicos realizados a la composición etnofarmacológica, demuestran que es posible que los metabolitos secundarios presentes en los extractos acuosos (Tabla 4) contribuyan al tratamiento de la hipertensión, porque de acuerdo con las actividades biológicas descritas para algunos compuestos fenólicos, tanto aislados como presentes en bebidas, vegetales o fruta, les hacen compuestos de interés en el campo medicinal por estar asociados con la prevención de enfermedades inducidas por estrés oxidativo como las enfermedades cardiovasculares. Los posibles efectos protectores informados están generalmente asociados con la actividad antioxidante de los mismos (Faudale et al. 2008).

Información bibliográfica reciente sobre estudios fitoquímicos y farmacológicos de las especies vegetales 


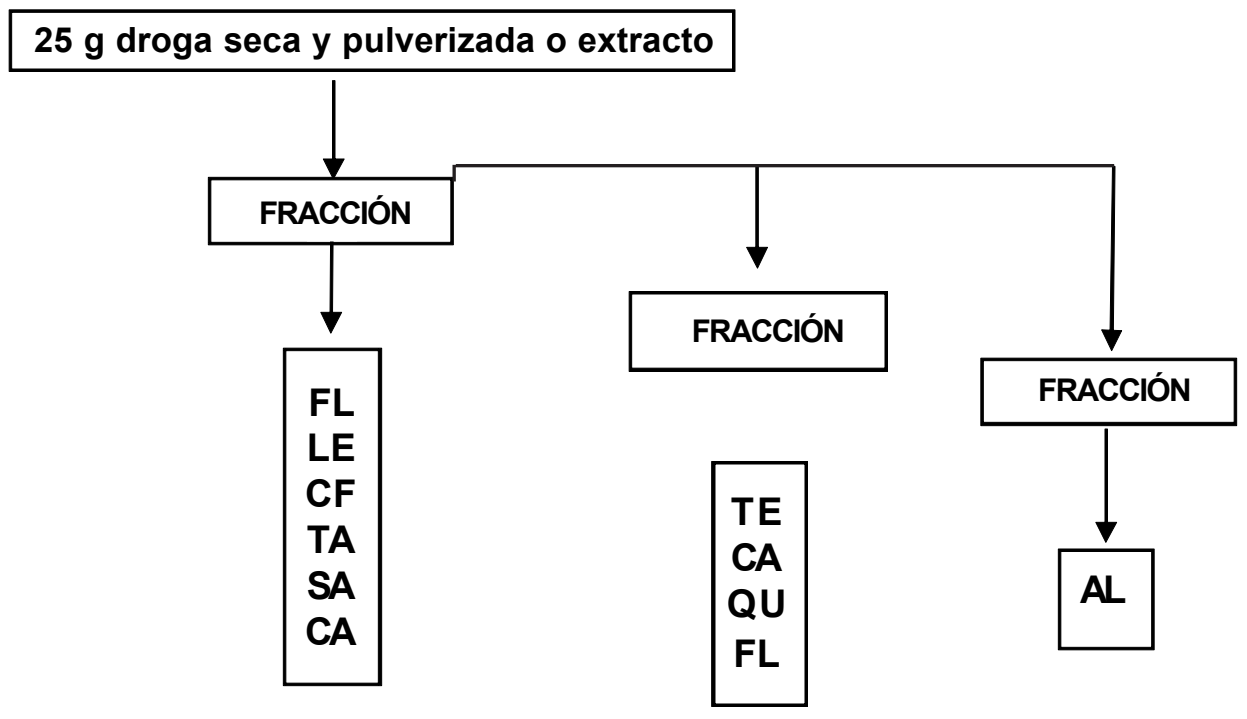

Figura 1. Flujograma resumen de la metodología utilizada

Tabla 3

Resultados de la marcha analítica de la composición etnofarmacológica para tratar la hipertensión

\begin{tabular}{|c|c|c|c|}
\hline Prueba & $\begin{array}{c}\text { Extracto acuoso } \\
\text { (fracción A) }\end{array}$ & $\begin{array}{l}\text { Solución orgánica } \\
\text { (fracción B) }\end{array}$ & $\begin{array}{c}\text { Solución acuosa ácida } \\
\text { (fracción C) }\end{array}$ \\
\hline Compuestos fenólicos & +++ & & \\
\hline Cumarinas & - & & \\
\hline Leucoantocianidinas & +++ & & \\
\hline Saponinas & - & & \\
\hline Taninos & - & & \\
\hline Flavonoides & - & - & \\
\hline Comp. lactónicos & - & ++ & \\
\hline Triterpénos y/o esteroides & & - & \\
\hline Quinonas alcaloides & & - & - \\
\hline
\end{tabular}

Negativo (-), Positivo (+), Muy positivo (++), Altamente positivo $(+++)$

usadas en la preparación de esta composición etnofarmacológica, demuestran la presencia de compuestos fenólicos, sobre todo en las hojas y cáscara de la guayaba (Psidium guajaba) (Marquina et al. 2008, Chen y Yen 2007); hojas, tallos y flores de mejorana (Majorana ortensis)(Dorman et al. 2004); bulbos de ajo (Allium sativum) (Bozin et al. 2008); flavonoides en hojas de mejorana (Majorana ortensis) (Lozaya et al. 2002), fruto de borojó (borojoa patinoi) (Mosquera et al. 2005), compuestos con reconocida actividad biológica antioxidante e hipotensora. Varios estudios han demostrado que la corteza y hojas de guanábana (Annona muricata) tienen actividad hipotensora en ratas (Hasrat et al. 1997, citado por Palomino 2007). Los extractos de ajo (Allium sativum) han demostrado efectos antihipertensivo en ratas (AlQattan, 2003).

La utilización de la medicina tradicional, ha venido ganado espacio cada vez más en la cura de esta enfermedad en el Chocó Biogeográfico, pues ya son muchos las casos y testimonios que dan fe de los poderes curativos de la medicina tradicional, que han trascendido hasta el punto de que médicos occidentales la recomienden. 


\section{AGRADECIMIENTOS}

Los autores agradecen al Grupo de Investigación Productos Naturales Marinos de la Universidad de Antioquia y en especial al MSc. Elkin Galeano por su valiosa colaboración.

\section{LITERATURA CITADA}

Abbassy, M.A., Abdelgaleil, S.A.M., Rabie, R.Y.A. 2009. Insecticidal and synergistic effects of majorana hortensis essential oil and some of its major constituents. Entomologia Experimentalis Et Applicata. 131: 225-32.

Betancur-Galvis, L.A., Saez, J., Granados, H. 1999. Antitumor and antiviral activity of Colombian medicinal plant extracts. Mem Inst Oswaldo Cruz. 94: $531-5$.

Bozin, B., Mimica-Dukic, N., Samojlik, I 2008. Phenolics as antioxidants in garlic (Allium sativum L., Alliaceae). Food Chem. 111: 925-9.

Brandelli, C.L.C., Giordani, R.B., De Carli, G.A. Indigenous traditional medicine: in vitro anti-giardial activity of plants used in the treatment of diarrhea. Parasitol Res. 104: 1345-9.

Cabrera R., Mantilla J. 1996. Plantas medicinales, cultivo y formas de preparación. Cusco: Ed. Centro de Estudios Regionales andinos «Bartolomé de las Casas».

Cáceres A. 1995. Plantas de uso medicinal en Guatemala. Tegucigalpa: Ed. Universitario. Universidad de San Carlos de Guatemala; p. 63-6.

Castro, O., Gutiérrez, J.M., Barrios, M. 1999. Neutralization of the haemorrhagic effect induced by Bothrops asper (Serpentes: Viperidae) venom with tropical plant extracts. Rev Biol Trop. 47: 605-15.

Chen, K.C., Hsieh, C.L., Huang, K.D. 2009. Anticancer activity of rhamnoallosan against DU-145 cells is kinetically complementary to coexisting polyphenolics in Psidium guajava budding leaves. J Agricult Food Chem. 57: 6114-22.

Chen, K.C., Hsieh, C.L., Peng, C.C. 2008. Brain derived metastatic prostate cancer DU-145 cells are effectively inhibited in vitro by guava (Psidium gujava L.) leaf extracts. Nutr C-An Int J. 58: 93-106.

Cheng, F.C., Shen, S.C., Wu, J.S.B. 2009. Effect of guava (Psidium guajava L.) leaf extract on glucose uptake in rat hepatocytes. JFood Sci. 74: H132H138.

Chen, H.Y., Yen, G.C. 2007. Antioxidant activity and free radical-scavenging capacity of extracts from guava (Psidium guajava L.) leaves source. Food Chem. 101: 686-94.

Choi, S.Y., Hwang, J.H., Park, S.Y. 2008. Fermented guava leaf extract inhibits LPS-induced COX-2 and iNOS expression in mouse macrophage cells by inhibition of transcription factor NFkappa B. Phytother Res. 22: 1030-4.

Chuang, PT, Shen, SC, Wu, NJ, et al. 2008. Anti-peroxidation effect of guava (Psidium guajava Linn.) leaf soluble solids in vitro and in streptozotocin/ nicotinamide-induced diabetic rats. J SciFood Agricult. 88: 2173-9.

Coppi, A., Cabinian, M., Mirelman, D. 2006. Antimalarial activity of allicin, a biologically active compound from garlic cloves. Antimicrob $\mathrm{Ag}$ Chemother 50: 1731-7.

De Almeida, A.P., Miranda, M.M.F.S., Simoni, I.C. 1998. Flavonol monoglycosides isolated from the antiviral fractions of Persea americana (Lauraceae) leaf infusion. Phytother Res. 12: 562-7.

Domergue, F., Helms, G.L., Prusky, D. 2000. Antifungal compounds from idioblast cells isolated from avocado fruits. Phytochemistry. 54: 183-9.

Dorman, H.J.D., Bachmayer, O., Kosar, M. 2004. Antioxidant properties of aqueous extracts from selected Lamiaceae species grown in Turkey. $J$ Agricult Food Chem. 52:762-70.

Dwyer, J. 2003. Is there a need to change the American diet? Dietary phytochemicals in cancer prevention and treatment. Adv Experim Med Biol. 401: 192-3.

Fontana, J.D., Lancas, F.M., Passos, M. 1998. Selective polarity- and adsorption-guided extraction purification of Annona sp. polar acetogenins and biological assay against agricultural pests. Applied Biochem Biotechnol70: 67-76.

Giordano, O. S. 2005. Química y aplicaciones de los productos naturales de plantas de la región de Cuyo. J Nat Prod 53: 803 .
Gupta, M. 1995.270 plantas medicinales iberoamericanas. Santiago: Programa Iberoamericano de Ciencia y Tecnología para el Desarrollo (CYTED).

Hamon, N.W. 1991. Elementos de fotoquímica y de farmacognosia. $10^{\mathrm{a}} \mathrm{ed}$. La Habana: Acribia; p. 116.

Hoque, M.D.M., Bari, M.L., Inatsu, Y. 2007. Antibacterial activity of guava (Psidium guajava L.) and neem (Azadirachta indica A. Juss.) extracts against foodborne pathogens and spoilage bacteria. Foodborne Pathog Dis. 4: 481-8.

Jaiarj, P., Khoohaswan, P., Wongkrajang, Y. 1999. Anticough and antimicrobial activities of Psidium guajava Linn. Leaf extract. $J$ Ethnopharmacol. 67: 203-12.

Kaileh, M., Vanden-Berghe, W., Boone, E. 2007. Screening of indigenous Palestinian medicinal plants for potential anti-inflammatory and cytotoxic activity. J Ethnopharmac. 113: 510-6 .

Kawagishi, H., Fukumoto, Y., Hatakeyama, M. 2001. Liver injury suppressing compounds from avocado (Persea americana). J Agricult Food Chem. 49: 2215-21.

Kawakami, Y., Nakamura, T., Hosokawa, T. 2009. Antiproliferative activity of guava leaf extract via inhibition of prostaglandin endoperoxide $\mathrm{H}$ synthase isoforms. Prostagl Leukotr Ess Fatty Acids. 80: 239-45.

Koua, K.H., Han, S.H. 1998. Evaluation of the larvicide effect of an aqueous extract of Persea americana (Miller 1768), Lauraceae, on Anopheles gambiae (Giles, 1902), Diptera Culicidae. Invertebr Reprod Develop. 34: $97-100$.

Lamiri, A., Lhaloui, S., Benjilali, B. 2001. Insecticidal effects of essential oils against Hessian fly, Mayetiola destructor (Say). Field Crops Res. 71:915 .

Leeja, L., Thoppil, J.E. 2007. Antimicrobial activity of methanol extract of Origanum majorana L. (Sweet marjoram). J Environ Biol. 28: 145-6.

Liaw, C.C., Chang, F.R., Lin, C.Y. 2002. New cytotoxic monotetrahydrofuran annonaceous acetogenins from Annona muricata. J NatProduc. 65: 4705 .

Lin, J., Puckree, T., Mvelase, T.P. 2002. Anti-diarrhoeal evaluation of some medicinal plants used by Zulu traditional healers. J Ethnopharmacol. 79: 53-6.

Liu, Z.F., Fang, F., Dong, Y.S. 2004. Experimental study on the prevention and treatment of murine cytomegalovirus hepatitis by using allitridin. Antivir Res. 61: 125-8.

Lovatis S., Castellani F. 1994. Alimentos y plantas medicinales. Bogota, DC: Editorial Norma S.A.; p.: 118-9.

Lozoya, X., Reyes-Morales, H., Chávez-Soto, M.A. 2002. Intestinal antispasmodic effect of a phytodrug of Psidium guajava folia in the treatment of acute diarrheic disease. J Ethnopharmacol. 83: 19-24.

Luna, J.D., dos Santos, A.F., de Lima, M.R.F. 2005. A study of the larvicidal and molluscicidal activities of some medicinal plants from northeast Brazil. J Ethnopharmacol. 97: 199-206.

Mahady, G.B., Pendland, S.L., Stoia, A. 2005. In vitro susceptibility of Helicobacter pylori to botanical extracts used traditionally for the treatment of gastrointestinal disorders. Phytother Res. 19: 988-91.

Marquina, V., Araujo, L., Ruiz, J., et al. 2008. Source. Arch Latinoam Nutr. 58: $98-102$

Menan, H., Banzouzi, J.T., Hocquette, A. 2006. Antiplasmodial activity and cytotoxicity of plants used in West African traditional medicine for the treatment of malaria. J Ethnopharmacol. 105: 131-6.

Miranda, M.M.F.S., Almeida, A.P., Costa, S.S. 1997. In vitro activity of extracts of Persea americana leaves on acyclovirresistant and phosphonoacetic resistant herpes simplex virus. Phytomedicine. 4: 347-52.

Mosquera, L. H., Ríos-Hurtado, A., Zapata-Porras, S. 2005. Obtención de una materia prima con valor agregado mediante secado por aspersión, a partir del fruto fresco de borojó (Borojoa patinoi Cuatr.). Revista Institucional Universidad Tecnológica del Chocó D.L.C. 23: 5-10.

Mukherjee, M., Das, A.S., Das, D. 2006. Role of oil extract of garlic (Allium sativum Linn.) on intestinal transference of calcium and its possible correlation with preservation of skeletal health in an ovariectomized rat model of osteoporosis. Phytother Res. 20: 408-1.

Nair, R., Chanda, S. 2007. In-vitro antimicrobial activity of Psidium guajava L. leaf extracts against clinically important pathogenic microbial strains. Braz J Microbiol. 38: 452-8.

Ojewole, J.A.O. 2006. Antiinflammatory and analgesic effects of Psidium 


\section{Bioetnia Volumen 6 No 1 (enero-junio), 2009}

guajava Linn. (Myrtaceae) leaf aqueous extract in rats and mice. Meth Find Experim Clin Pharmacol. 28: 441-6.

Ojewole, J.A.O., Amabeoku, G.J. 2006. Anticonvulsant effect of Persea americana Mill (Lauraceae) (Avocado) leaf aqueous extract in mice. Phytother Res. 20: 696-700.

Osorio, E., Arango, G.J., Jiménez, N. 2007. Antiprotozoal and cytotoxic activities in vitro of Colombian Annonaceae. JEthnopharmacol. 111:6305 .

Pachanawan, A., Phumkhachorn, P., Rathanachaikunsopon, P. 2008. Potential of Psidium guajava suplemented fisch diets in controlling aeromonas hydrophila infection in tilapia (Oreochromis niloticus). J Biosci Bioengin. 106: 419-24.

Padma, P., Pramod, N.P., Thyagarajan, S.P. 1998. Effect of the extract of Annona muricata and Petunia nyctaginiflora on herpes simplex virus. $J$ Ethnopharmacol. 61: 81-3.

Palomino F. C., 2007. Efecto del extracto etanólico de hojas de Annona muricata L. (Guanábana) sobre la hiperglicemia inducida con aloxano en ratas. Tesis de grado para optar el título de Magister en Farmacología con Mención en Farmacológica Experimental. Tegucigalpa: Universidad Nacional Mayor de San Marcos.

Pelegrini, P.B., Murad, A.M., Silva, L.P. 2008. Identification of a novel storege glycine-rich peptide from guava (Psidium guajava) sedes with activity against Gram-negative bacteria. Peptides. 29: 1271-9.

Pérez S.E. 1989. Actividad anticoagulante y fibrinolitica del Allium sativum «ajo» en el Oryctolgagus cunniculus. Tesis Bach. Farmacia Universidad de Trujillo, Perú.

Peris J.B., Stubing G., Vanaclocha B. 1995. Fitoterapia aplicada. Valencia: Colegio Oficial de Farmacéuticos de Valencia;p. 628.

Polat, Z.A., Vural, A., Ozan, F. 2008. In vitro evaluation of the amoebicidal activity of garlic (Allium sativum) extract on Acanthamoeba castellanii and its cytotoxic potential on corneal cells. J Ocular Pharmacol Therap. 24: $8-14$.

Rai, P.K., Jaiswal, D., Mehta, S. 2009. Anti-hyperglycaemic potential of Psidium guajava raw fruit peel. Indian J Med Res. 129: 561-5.

Ramírez, R., Mostacero, J., Araujo, E., Mejía, F., Peláez, F., Medina, D. 1998
Vegetales empleados en medicina tradicional norperuana. Lima: Editorial Centro de Estudios Regionales Andinos «Bartolomé de las Casas»; p. 123, 28-38, 40-53.

Reddy, K.R.N., Reddy, C.S., Muralidharan, K. 2009. Potential of botanicals and biocontrol agents on growth and aflatoxin production by Aspergillus flavus infecting rice grains. Food Control. 20: 173-8.

Santos, F.A., Rao, V.S.N., Silveira, E.R. 1998. Investigations on the antinociceptive effect of Psidium guajava leaf essential oil and its major constituents. Phytother Res. 12: 24-7.

Sarer E., Scheffer J.J., Baerheim S.A. 1982. Monoterpenos in the essential oil of Origanum majorana. Planta Med. 46: 236-9.

Seo, N, Ito, T, Wang, N.L. 2005. Anti-allergic Psidium guajava extracts exert an antitumor effect by inhibition of $\mathrm{T}$ regulatory cells and resultant augmentation of Th1 cells. Antica Res. 25: 3763-70.

Universidad de Lima. 1994. Catálogo de plantas medicinales. Lima: Facultad de Ingeniería Industrial.

Vera R.R., Chane-Ming J. 1999. Chemical composition of the essential oil of marjoram (Origanum majorana L.) from reunion Island. Food Chem. 66: 143-5.

Yamanaka, F., Hatano, T., Ito, H. 2008. Antibacterial effects of guava tannins and related polyphenols on Vibrio and Aeromonas species. Nat Prod Commun. 3: 711-20.

Yang, Y.C., Lee, S.H., Clark, J.M. 2009. Ovicidal and adulticidal activities of Origanum majorana essential oil constituents against insecticide-susceptible and pyrethroid/malathion-resistant Pediculus humanus capitis (Anoplura: Pediculidae). J Agricult Food Chem. 57: 2282-7.

Yazdanparast, R., Shahriyary, L. 2008. Comparative effects of Artemisia dracunculus, Satureja hortensis and Origanum majorana on inhibition of blood platelet adhesion, aggregation and secretion. Vasc Pharmacol. 48: $32-7$.

William A.R., Thomson D.M. 1981. Guía práctica ilustrada de las plantas medicinales. Barcelona: Editorial Blume; p. 220.

Zahir, A.A., Rahuman, A.A., Kamaraj, C. 2009. Laboratory determination of efficacy of indigenous plant extracts for parasites control. Parasitol Res. 105: 453-61. 